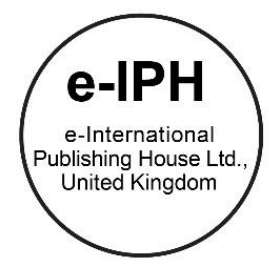

\title{
Eye Movements Behaviour in Reading Different Text Sizes among University Students
}

\author{
Noor Halilah Buari'1,2, Anis Nur Fazlyana Md-Isa' \\ ${ }^{1}$ Centre for Optometry Studies, ${ }^{2}$ Optometry \& Visual Sciences Research Centre (iROViS), Faculty of Health Sciences, \\ Universiti Teknologi MARA Cawangan Selangor, Bandar Puncak Alam 42300 Selangor, Malaysia \\ noorhalilah.buari@gmail.com, anisfazlyana@gmail.com \\ Tel: +60126121582
}

\begin{abstract}
Reading efficiency is one of the main concerns among the teachers, publishers, and also eye care practitioners. The size of the text was among factor that might affect the reading. The eye movement behaviour was studied in six different text legibility. The saccades and fixation were recorded and tracked among twenty-five university students. Significant changes in eye movements behaviour in term of saccades and fixations occurred when the university students read passages with different text legibility. The eye movements behaviour was able to adapt to the changes in shape, and size of presented reading materials for better understanding of reading.
\end{abstract}

Keywords: eye movements; saccadic; fixation; reading

eISSN: 2398-4287 ( 2019. The Authors. Published for AMER ABRA cE-Bs by e-International Publishing House, Ltd., UK. This is an open access article under the CC BYNC-ND license (http://creativecommons.org/licenses/by-nc-nd/4.0/). Peer-review under responsibility of AMER (Association of Malaysian Environment-Behaviour Researchers), ABRA (Association of Behavioural Researchers on Asians) and cE-Bs (Centre for Environment-Behaviour Studies), Faculty of Architecture, Planning \& Surveying, Universiti Teknologi MARA, Malaysia.

DOI: https://doi.org/10.21834/e-bpj.v4i12.1916

\subsection{Introduction}

Reading is one thread of learning. Reading is essential to full connection in every daily activity which involves of vocational, social, and leisure activities. By reading, one's can have better vocabularies, enriched general knowledge, broaden oral language skills, better academic attainment, improved word recognition processes (Takeuchi et al., 2016) and also developed spoken fluency (Mol \& Bus, 2011; Stanovich \& Cunningham, 1992). Through the knowledge gained in reading, it helps people to develop intellectual and creativity. The activity of reading comprised of several aspects, such as recreational reading and formal reading (Schutte \& Malouff, 2004). Reading activities not only limited to reading the newspaper but also include reading food or medicine labels, brochures, reading emails and also reading various types of formal books and casual books. Since the reading materials are available in different kinds and styles, it indicates that the presentation of reading materials can be in many ways. The reading materials are differed in term of font types, size of texts, colour and layout. These factors could affect the outcome of the reading. It was showed in various studies that the text size significantly affects the reading performance (Alotaibi, 2007; Arditi \& Cho, 2007; Legge, Pelli, Rubin, \& Schleske, 1985). According to Legge et al., readers with normal vision, reading speed increased as the text size enlarged (Legge et al., 1985). The increment of text size not only effected the reading among normal vision reader but also among those with blurry of vision (Alotaibi, 2007).

Reading encompasses multiple processes, including decrypting and encrypting of written words for visual processing and translating the printed components for the linguistic outcome (Hoover \& Gough, 1990). The reading model starts with attention in which the eye change attention to the next word or letter of the text (Rayner, 2009; Rayner, Slattery, \& Bélanger, 2010). Then the oculomotor system gives a signal to start a saccadic movement to move to the next word or letter. In between saccadic movement, the eye makes a stop to fixate and keep the word stable. During fixation, the impulse extracts the information. The brain received the extracted information for neural processing such as visuo-spatial attention, orthographic, phonological, lexical and semantic processing. The process repeated

eISSN: 2398-4287 @ 2019. The Authors. Published for AMER ABRA cE-Bs by e-International Publishing House, Ltd., UK. This is an open access article under the CC BYNC-ND license (http://creativecommons.org/licenses/by-nc-nd/4.0/). Peer-review under responsibility of AMER (Association of Malaysian Environment-Behaviour Researchers), ABRA (Association of Behavioural Researchers on Asians) and cE-Bs (Centre for Environment-Behaviour Studies), Faculty of Architecture, Planning \& Surveying, Universiti Teknologi MARA, Malaysia. DOI: https://doi.org/10.21834/e-bpj.v4i12.1916 
until the reading ended (Hung \& Ciuffreda, 2002; Rayner, 2009). There are a few basic types of eye movement, which are saccades, smooth pursuits, vergence, fixations and vestibule-ocular movements (Purves, Augustine, \& Fitzpatrick, 2001). Saccades are rapid, ballistic movement of the eyes that abruptly change the point of fixation. Smooth pursuit is much slower than tracking movements of the eyes designed to keep a moving stimulus on the fovea. Fixation is the brief stop between saccades. The saccades are separated by times when the eyes are in stills position (fixations). During fixation, the new information is encoded, while during saccades, the vision is suppressed (Rayner et al., 2010). Regression allows the rereading of previously fixated words that they have missed, forgotten or are unsure (Booth \& Weger, 2013).

Many factors can influence eye movement behaviour in the text presentation, including the size of the text (Rayner, 2009; Rayner \& Fischer, 1996; Rayner et al., 2010). Several studies had shown that the size of text changed reading and eye movement behaviour (Beymer, Russell, \& Orton, 2008; Franken, Podlesek, \& Možina, 2015; Masulli et al., 2018; Yen, Tsai, Chen, Lin, \& Chen, 2011). A different saccadic movement behaviour occurred when reading the bigger size of text (Franken et al., 2015; Masulli et al., 2018). The changes happened among the schoolchildren who read the text at the size of 25pt and 30pt, which the amplitude of saccade movement became wider to move from one word to another (Masulli et al., 2018). Moreover, the number of fixation increased and the fixation duration shorter when the size of the text enlarged. Franken et al. investigated the saccade length and fixation in eight print size when reading text on the LCD screen (Franken et al., 2015). The findings showed that the visual angle in saccade length became more significant when the size of the text increased. However, the saccadic behaviour remains similar at smaller print size until it reaches 32pt text size, then only the saccadic eye movement changed its behaviour. Among the eight text sizes, the fixation duration changed significantly at a text size of 20-pt (Franken et al., 2015). Beymer et al. (2008) studied the effect of font size towards online reading, varying from $10 \mathrm{pt}, 12 \mathrm{pt}$ and $14 \mathrm{pt}$. The results showed that the font size had a slight influence in reading speed, where the participant read slightly faster with larger fonts. The fixation duration was longer with smaller text sizes (10 pt) as compared to larger text size (12 pt) when reading an online text (Beymer et al., 2008). A study by Yen (2011) to investigate the eye movement behaviour when reading Chinese character with different print size showed that the frequency of fixation was found to be higher with larger print size (32 pixels) compared to the smaller print size (24 pixels) (Yen et al., 2011).

Eye movements behaviour has been shown extensively used to explore the cognitive process of reading (Rayner, 2009). Several studies have proven that eye movement behaviour changed as the size of the text was altered. The changes happened in eye movement behaviours such as fixations and saccades is the micro-processing during the reading process. The investigations were done using a limited text size or focused on the electronic sources of reading material such as online reading or reading from the electronic screen. Daily reading not only occurred using electronic display but also on printed or hard copy reading materials such as reading books, newspapers, food label, brochure, medicine label and many more. There are variations in eye movement behaviour from previous studies, and there is a lack of study that compared the reading at different print size on printed materials. Therefore, the study intended to investigate the eye movement behaviour at different text size among the university students.

\subsection{Materials and Methods}

A cross-sectional comparative study was conducted to investigate the eye movement behaviour in different size of text among young adult university students. Twenty-five university students aged within 18 to 30 years participated in this study. The sample size calculation based on the previous study (Choi, Lowder, Ferreira, Swaab, \& Henderson, 2017) using the formula of $n=(Z \sigma \div \Delta)^{2}$. The standard deviation $(\sigma)$ was 2.3 ; the $Z$ was 1.96 for $95 \%$ of the confidence interval, and precision $(\Delta)$ was at 1 . The participants included those with best-corrected distance and near visual acuity of $6 / 9$ and $\mathrm{N} 6$ or better, respectively. The participants' criteria also included low to a moderate habitual refractive error of short-sightedness and long-sightedness (sphere correction between +2.00DS until -3.00DS and astigmatism up to $-1.00 \mathrm{DC}$ ). The exclusion criteria were the participants with any binocular vision problems and those with ocular disorders and pathologies.

The reading stimuli used Malay reading passages extracted from Shauqiah-Ai Hong-Halilah Reading Passage Compendium (SAHRPC) (Chen, Buari, \& Shauqiah, 2017). The SAHRPC contained 42 passages and compiled into three sets of 13 passages. Each set comprised of 13 Arial print sizes ranged from 7-pt to 52-pt. The passages arranged in a decreasing 0.1-step logarithmic scale, from $1.2 \log M A R$ to 0.0 logMAR. Thirteen passages encompassed in each set of eight-pages flip design that printed on a matte type A3 size paper in landscape orientation. Six Malay passages from SAHRPC was selected for reading stimuli in this study. The passages contained a paragraph of 4 to 5 lines and 50 words. It was extracted from the Malay language textbook used by the primary school under the Malaysian Ministry of Education. The text size comprised of 5pt, 8pt, 14pt, 20pt, 30pt and 52pt. The legibility of text sizes was equivalent with $0.2 \log M A R, 0.4 \log M A R, 0.6 \log M A R, 0.8 \log M A R, 1.0 \log M A R$ and $1.2 \log M A R$. The chosen six text sizes mimic real reading material which the text size of 52pt represents the newspaper headlines. 30pt equivalent to sub-headlines of newspaper and children's books, 20pt is similar to books for ages of 7 to 8 years, 14 pt is comparable to grade 1 to 3 children's textbooks, 8 pt is equivalent to small column newsprint, and 5 pt is equal to small print Bible and footnotes.

The Dikablis Eye Tracking Glasses Professional (Ergoneer, Germany) is a head-based eye-tracking system, which requires the participants to wear a glasses-like frame. It has two miniature cameras facing in front of the eye to record and detect the eye movement of the test person. The camera records a black-and-white video of the eye with a resolution of $384 \times 288$ pixels. There is another miniature camera called the scene camera located on the nasal part of the glasses. The scene camera functions to record the viewing scene of the participant with a resolution of $1920 \times 1080$ pixels during data recording. The scene camera can be adjusted up to $12^{\circ}$ upward and $81^{\circ}$ downward. The eye cameras are freely adjustable via flexible swan-neck design to fit the interpupillary distance of the wearer. The head unit can be freely adjusted to suit the size of the test person's head using the cord stopper on the drawstring. The head unit also 
can be worn over wearer's spectacles or polarised glasses. The recorded data were sent and analyzed by the D-Lab software version 3.0, installed on the computer. The Dikablis Eye Tracking Glasses Professional offers a range of data visualization such as eye tracker, heat maps, glance flow diagram and more.

The participants were attended individually, and the experiment took place in a quiet room with ambient room lighting. All participants gave written informed consent before the experiment. The university research ethics committee approved the study, and it has adhered to the declaration of Helsinki (Approval No: REC/426/17). After the participants passed the screening procedures, the participants sat facing the reading stimuli (The Malay passage) that placed on the reading stand at the working distance of $40 \mathrm{~cm}$. The passages were covered beforehand to avoid recitation by the participants. The participants' wore the Dikablis eye tracker along with their spectacle corrections. The calibration of the eye tracker was done before starting the test procedure. The participants were required to read the passage loudly with a regular rate of reading speed. The eye movement behaviour was recorded simultaneously by the Dikablis eye tracker during the reading process. The experiment for each text size was conducted separately.

The data of the eye movement behaviour was recorded and sent to the D-Lab software for further analysis. The eye movement behaviour comprises of the number of saccadic, saccadic angle, the number of fixation duration and fixation duration. Statistical analysis was performed using SPSS version 21.0. The descriptive data of eye movement behaviour in reading at different text sizes among university students include the median, quartile, mean and standard deviation. As the comparison of eye movement behaviour for the right eye and the left eye showed no significant differences ( $p>0.05)$, the eye movement behaviour analysis used right-eye data. The Kolmogorov-Smirnov normality test showed that the data was not normally distributed $(p>0.05)$. Hence, the eye movement behaviours in different text sizes among university students were compared using the Kruskal-Wallis test. The statistical significance was set at $p<0.05$.

\subsection{Results}

A total of twenty-five (25) university students aged $22.28 \pm 1.46$ years participated in this study. The participants comprised of 19 (76.0\%) female and $6(24 \%)$. Table 1 tabulated the demographic data of the eye movements behaviour among university students.

Table 1. The eye movement behaviour in six different text sizes

\begin{tabular}{lcccc}
\hline Print sizes & Number of saccadic $(\mathrm{n})$ & Saccadic angle $\left({ }^{\circ}\right)$ & number of fixation $(\mathrm{n})$ & Fixation duration $(\mathrm{ms})$ \\
\hline $5 \mathrm{pt}$ & $5.76 \pm 4.24$ & $6.25 \pm 1.73$ & $6.99 \pm 5.61$ & $698.49 \pm 58.52$ \\
$8 \mathrm{pt}$ & $9.60 \pm 6.36$ & $6.23 \pm 1.82$ & $14.52 \pm 7.85$ & $703.61 \pm 58.12$ \\
$14 \mathrm{pt}$ & $13.04 \pm 7.92$ & $6.03 \pm 1.59$ & $18.64 \pm 10.86$ & $546.89 \pm 62.89$ \\
$20 \mathrm{pt}$ & $20.72 \pm 7.92$ & $6.48 \pm 1.97$ & $24.80 \pm 11.06$ & $580.26 \pm 67.54$ \\
$30 \mathrm{pt}$ & $43.82 \pm 13.67$ & $6.92 \pm 1.90$ & $47.40 \pm 12.50$ & $414.30 \pm 75.86$ \\
$52 \mathrm{pt}$ & $60.56 \pm 18.54$ & $9.21 \pm 2.69$ & $69.68 \pm 18.33$ & $285.25 \pm 75.57$ \\
\hline
\end{tabular}

The comparison of the eye movement behaviour between different text sizes was tested using the Kruskal-Wallis test. Fig. 1 showed a comparison of the number of saccadic and saccadic angle in six text sizes. The number of saccadic movement made by the university students were significantly different when reading Malay passages at different text sizes, $X^{2}(5)=114.23, p<0.001$. The number of saccades increased gradually when the text size became larger. A significant increment in the number of saccades occurred at 20-pt print size. The saccade angle also showed a significant difference at different text sizes, $X^{2}(5)=20.21, p=0.001$. As the text size increased the saccadic angle became broader and more substantial. The drastic changes in saccadic angle happened when the university students read passages of 52 pt text size.

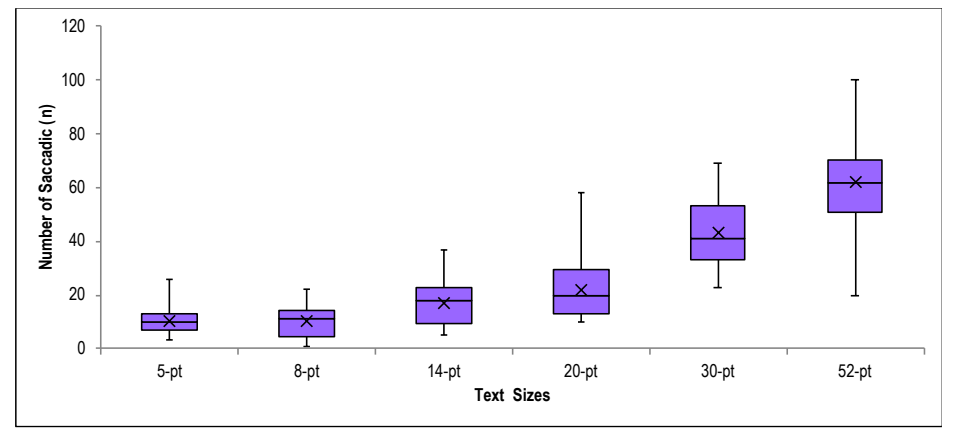




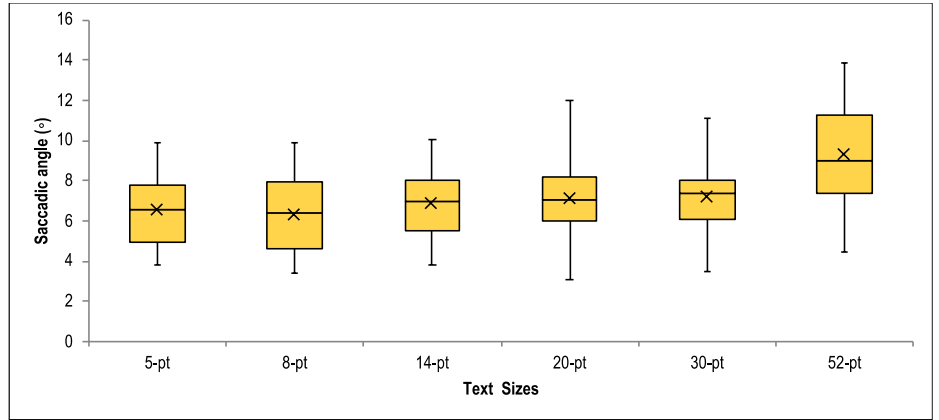

Fig. 1: Box plot on the number of the saccade (above) and saccadic angle (below) across six different text sizes. The error bar shows the maximum and minimum values. The horizontal line in the middle of the box shows the median. The lower edge of the box represents the first quartile, and the upper edge of the box represents the third quartile. Symbol $X$ in the middle of the box represents the mean value.

Another eye movement behaviour that was investigated includes the number of fixation and fixation duration as per charted in Fig. 2. The analysis showed a significant difference, $X^{2}(5)=108.95, p<0.001$ in the number of fixation when reading passages at different text sizes. The university students tended to make more stop during reading when the text sizes increased. The number of fixation was increased steadily from 5-pt to 20-pt. However, the number of fixation increased sharply for text size of 30-pt and 52-pt. The fixation duration indicated how long the eye stops during reading. When reading the passages at different text sizes, the fixation duration was significantly longer at smaller text sizes, $X^{2}(5)=48.01, p<0.001$. The result indicated that the eye spent less time during a stop as the size of the text became larger.
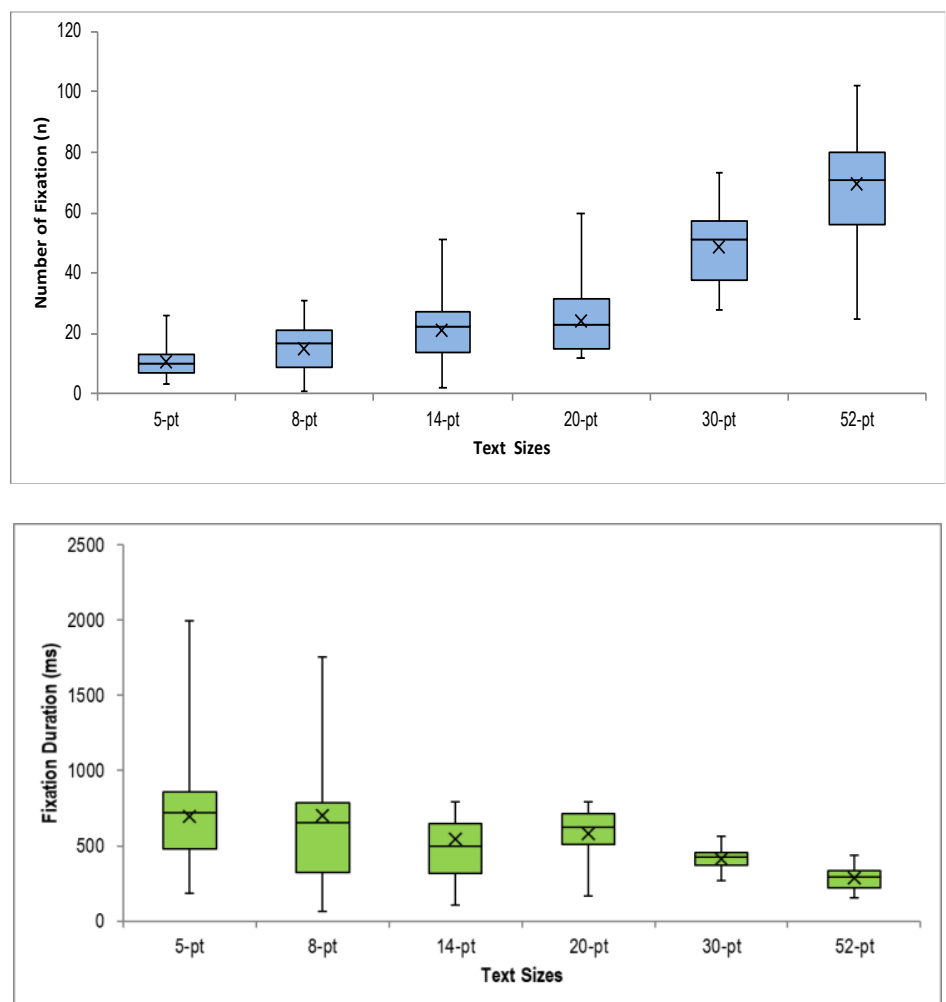

Fig. 2: Box plot on the number of fixation (above) and fixation duration (below) across six different text sizes. The error bar shows the maximum and minimum values. The horizontal line in the middle of the box shows the median. The lower edge of the box represents the first quartile, and the upper edge of the box represents the third quartile. Symbol $X$ in the middle of the box represents the mean value.

\subsection{Discussions}

The study investigated eye movement behaviour in term of saccadic eye movement and fixation. The saccadic angle also became more substantial as the text size increased. The significant eye movement behaviour occurred at a text size of 20-pt for the number of saccadic and 52-pt for the saccadic angle. The findings indicated that the eye made more and wider saccadic movements when text size became bigger. The saccadic movement changed when reading a larger size of text (Franken et al., 2015; Masulli et al., 2018). The amplitude of the saccade movement enlarged as the size of text increased when the schoolchildren aged 7 to 12 years read the text of $25 \mathrm{pt}$ and 30pt (Masulli et al., 2018). In the investigation of shape and size of text on the LCD screen, it was found that saccade lengths in degrees of visual angle became wider at the larger text size despite any font type (Franken et al., 2015). This study chooses eight print size 
ranging from 16pt to 32pt. At smaller text size the saccade length was similar; however, it became significantly wider at 32pt text size. Franken et al. (2015) findings mirrored to the current study, which the eye tended to make broader saccadic angle movement at larger text size. However, some other studies showed no significant difference in a saccadic movement when reading different print size (Beymer et al., 2008; Yen et al., 2011). In Baymer et al. (2008) study's, saccade length and number of saccade were similar across the different print size. The result in Baymer's might be due to the small text size chosen as reading stimuli in the experiment which 10pt, 12pt and 14pt (Beymer et al., 2008). As per revealed in the current study and also Franken's et al. study, the saccadic movement was similar across smaller text size. It only revealed changes in eye movement behaviour at larger text size. The increment of saccade eye movement behaviour as the text size became more substantial might due to the presentation of the text. When the text size increased, the size of the overall text presentation became larger to fit in the whole passage. The condition caused the eye made more movement to jump from a word to another to enable the reader to read the whole passage. Therefore, it increased the number of saccade and saccadic lengths. The variations could be due to the changes in visual searching strategy during reading different text size.

The study showed that the number of fixation increased as the text size enlarged. However, the fixation duration became longer at smaller text size. The fixation changed significantly at a text size of 30-pt. Fixation is the eye movement behaviour, which the eye make a stop during reading to extract the information on the text for brain processing. At smaller text size, the eye made less stopping movement behaviour but stopped a long time to extract and process the visual information as compared to the larger text size. Several studies showed a similar pattern of findings, which the eye made less fixation and longer fixation duration at smaller text size (Beymer et al., 2008; Franken et al., 2015; Masulli et al., 2018; Yen et al., 2011). The frequency of fixation or stopping behaviour was found to be higher with larger print size (32 pixels) compared to the smaller print size (24 pixels) (Yen et al., 2011). The fixation duration was significantly longer with smaller text sizes (10 pt) compared to larger print size (12 pt) when reading an online text (Beymer et al., 2008). Besides, Yen et al. (2011) found that the fixation duration was shorter for 32 pixels than 24 pixels when reading printed Chinese character. In another study that selected eight text size showed that the fixation duration changed significantly at a text size of 20-pt (Franken et al., 2015). The finding was about similar to the current study, which the fixation behaviour changed at the text size of 30-pt. The results showed changes in fixation behaviour at the different text size, which available in various reading materials.

The eye movement behaviour in fixation that increases in the number of fixation in larger text size could be due to broader text presentation. Broader text presentation caused the eye need to make a frequent stop to extract information for visual processing for the whole passage. Whereby, in smaller text size that causes the eye to spend longer time during fixation could be due to crowing effect of the text on smaller text presentation (Bricolo, Salvi, Martelli, Arduino, \& Daini, 2015; Masulli et al., 2018). Crowding is a condition that characterises normal periphery restrictive letter identification when other letters surround the object (Rayner, 2009). The smaller text size presentation caused the letters or words to confine, and the eye needs to make a more extended stop to focus and extract visual information. Another reason could be the other letters or words around the fixation point interfere the visual extraction processing. The eye movement behaviour revealed in the reader responds which they did not have to concentrate more to read broad text presentation (Sharmin, Špakov, \& Räihä, 2012). However, the readers had difficulty to read smaller text presentation. The condition explained the result of fixation behaviour that decreased in number and longer fixation duration when reading the smaller text size. The changes in fixation behaviour also suggested the visual attentional strategies by the eye to adapt to changes in different reading stimuli.

\subsection{Conclusion}

In conclusion, changes in eye movements behaviour occurred when university students read passages in different text sizes. The eyes made more saccadic eye movements as the text size increased. The saccadic angle became significantly greater when reading a larger text size. Fixations or stopping behaviour showed an increment with increasing text sizes. The time eyes spent during the stop was longer at smaller text size. The changes in saccade eye movement suggested an alteration in visual searching strategy, while modification in fixation behaviour indicated changes in visual attentional strategy during reading. The eye movements behaviour was able to adapt to the changes in pattern, shape, and size of presented reading materials. This behaviour could be an indication of modification in cognitive and brain processing to allow better comprehension when reading in the different reading material presentation.

\section{Acknowledgements}

Funding for this study granted from UiTM REI grant (Ref No:600-IRMI/REI 5/3 (016/2018)).

\section{References}

Alotaibi, A. Z. (2007). The effect of font size and type on reading performance with Arabic words in normally sighted and simulated cataract subjects. Clinical and Experimental Optometry, 90(3), 203-206. https://doi.org/10.1111/j.1444-0938.2007.00123.x

Arditi, A., \& Cho, J. (2007). Letter case and text legibility in normal and low vision. Vision Research, 47, 2499-2505.

Beymer, D., Russell, D., \& Orton, P. (2008). An eye tracking study of how font size and type influence online reading. Proceedings of the 22nd British HCI Group Annual Conference on People and Computers: Culture, Creativity, Interaction, BCS HCI 2008, 2, 15-18.

Booth, R. W., \& Weger, U. W. (2013). The function of regressions in reading: Backward eye movements allow rereading. Memory \& Cognition, 41(1), 82-97. https://doi.org/10.3758/s13421-012-0244-y 
Bricolo, E., Salvi, C., Martelli, M., Arduino, L. S., \& Daini, R. (2015). The effects of crowding on eye movement patterns in reading. Acta Psychologica, 160(January), 2334. https://doi.org/10.1016/j.actpsy.2015.06.003

Chen, A.-H., Buari, N. H., \& Shauqiah, J. (2017). The Development of SAH Reading Passage Compendium: A Tool for the Assessment of Reading Performance Related to Visual Function. International Education Studies, 10(12), 30. https://doi.org/10.5539/ies.v10n12p30

Choi, W., Lowder, M. W., Ferreira, F., Swaab, T. Y., \& Henderson, J. M. (2017). Effects of word predictability and preview lexicality on eye movements during reading: A comparison between young and older adults. Psychology and Aging, 32(3), 232-242. https://doi.org/10.1037/pag0000160

Franken, G., Podlesek, A., \& Možina, K. (2015). Eye-tracking study of reading speed from LCD displays: Influence of type style and type size. Journal of Eye Movement Research, 8(1), 1-8. https://doi.org/10.16910/jemr.8.1.3

Hoover, W. A., \& Gough, P. B. (1990). The Simple View of Reading. Reading and Writing, 2, 127-160.

Hung, G. K., \& Ciuffreda, K. J. (2002). Models of the Visual System. New York: Kluwer Academic/Plenum Publishers. https://doi.org/10.1007/978-1-4757-5865-8

Legge, G. E., Pelli, D. G., Rubin, G. S., \& Schleske, M. M. (1985). Psychophysics of reading--I. Normal vision. Vision Research, 25(2), $239-252$.

Masulli, F., Galluccio, M., Gerard, C. L., Peyre, H., Rovetta, S., \& Bucci, M. P. (2018). Effect of different font sizes and of spaces between words on eye movement performance: An eye tracker study in dyslexic and non-dyslexic children. Vision Research, 153(June), 24-29. https://doi.org/10.1016/j.visres.2018.09.008

Mol, S. E., \& Bus, A. G. (2011). To Read or Not to Read: A Meta-Analysis of Print Exposure From Infancy to Early Adulthood. Psychological Bulletin, 137(2), 267-296. https://doi.org/10.1037/a0021890

Purves, D., Augustine, G., \& Fitzpatrick, D. (2001). Types of Eye Movements and Their Functions, 1-2.

Rayner, K. (2009). Eye Movements and Attention In Reading, Scene Perception, and Visual Search. Quarterly Journal of Experimental Psychology, 62(8), 1457-1506. https://doi.org/10.1080/17470210902816461

Rayner, K., Slattery, T. J., \& Bélanger, N. N. (2010). Eye movements, the perceptual span, and reading speed. Psychonomic Bulletin \& Review, 17(6), 834-839. https://doi.org/10.3758/PBR.17.6.834

Schutte, N. S., \& Malouff, J. M. (2004). University student reading preferences in relation to the Big Five personality dimensions. Reading Psychology, 25(4), 273-295. https://doi.org/10.1080/02702710490522630

Sharmin, S., Špakov, O., \& Räihä, K. J. (2012). The effect of different text presentation formats on eye movement metrics in reading. Journal of Eye Movement Research, 5(3), 1-9. https://doi.org/10.16910/jemr.5.3.3

Stanovich, K. E., \& Cunningham, A. E. (1992). Studying the consequences of literacy within a literate society: The cognitive correlates of print exposure. Memory \& Cognition, 20(1), 51-68. https://doi.org/10.3758/BF03208254

Takeuchi, H., Taki, Y., Hashizume, H., Asano, K., Asano, M., Sassa, Y., ... Kawashima, R. (2016). Impact of reading habit on white matter structure: Cross-sectional and longitudinal analyses. Neurolmage, 133, 378-389. https://doi.org/10.1016/j.neuroimage.2016.03.037

Yen, N. S., Tsai, J. L., Chen, P. L., Lin, H. Y., \& Chen, A. L. P. (2011). Effects of typographic variables on eye-movement measures in reading Chinese from a screen. Behaviour and Information Technology, 30(6), 797-808. https://doi.org/10.1080/0144929X.2010.523900 